\title{
BMJ Open Representations of the health value of vitamin D supplementation in newspapers: media content analysis
}

\author{
Timothy Caulfield, ${ }^{1}$ Marianne I Clark, ${ }^{1}$ James P McCormack, ${ }^{2}$ Christen Rachul, ${ }^{3}$ \\ Catherine $\mathrm{J} \mathrm{Field}{ }^{4}$
}

To cite: Caulfield T, Clark MI, McCormack JP, et al. Representations of the health value of vitamin $D$ supplementation in newspapers: media content analysis. BMJ Open 2014;4: e006395. doi:10.1136/ bmjopen-2014-006395

- Prepublication history for this paper is available online To view these files please visit the journal online (http://dx.doi.org/10.1136/ bmjopen-2014-006395).

Received 18 August 2014 Revised 12 December 2014 Accepted 15 December 2014

CrossMark

For numbered affiliations see end of article.

Correspondence to

Timothy Caulfield;

Caulfield@ualberta.ca

\section{ABSTRACT}

Objective: To examine the nature of media coverage of vitamin $D$ in relation to its role in health and the need for supplements.

Design: Media content analysis.

Setting: Print articles from elite newspapers in the UK, the USA and Canada.

Participants: 294 print newspaper articles appearing over 5 years (2009-2014).

Results: Newspaper coverage of vitamin $D$ generally supported supplementation. The most common framing of vitamin $D$ in print articles was "adequate vitamin $D$ is necessary for good health." Articles also framed vitamin $D$ as difficult to obtain from food supply and framed vitamin $D$ deficiency as a widespread concern. In discussions of supplementation, $80 \%$ articles suggested supplementation is or may be necessary for the general population, yet almost none of the articles discussed the potential harms of vitamin D supplementation in any detail.

Print articles named 40 different health conditions in relationship to vitamin $\mathrm{D}$. The most commonly cited conditions included bone health, cancer and cardiovascular health. Although print articles referred to a wide range of scholarly research on vitamin $D$ with varying degrees of endorsement for supplementation, a general tone of support for vitamin D supplementation in media coverage persisted.

Conclusions: Newspaper articles conveyed overall support for vitamin D supplementation. News articles linked vitamin $D$ to a wide range of health conditions for which there is no conclusive scientific evidence. Media coverage downplayed the limitations of existing science and overlooked any potential risks associated with supplementation.

\section{INTRODUCTION}

Despite numerous studies and policy recommendations that have questioned the health value of dietary supplementation, ${ }^{12}$ the sale of supplements is a vast multibillion dollar industry. Research has shown that between $35 \%$ and $50 \%$ of the Canadian and US

\section{Strengths and limitations of this study}

- This study examines a large sample of print media articles from venues with high circulation rates.

- This study demonstrates that media coverage links vitamin $D$ to a wide range of health conditions for which there exists no conclusive evidence.

- This study does not examine internet-based news sources, which are becomingly an increasingly important source of health information.

population, including children, take some form of dietary supplements, ${ }^{3-6}$ primarily because they believe the food supply is not sufficient to meet their needs and that supplements will improve health and offer protection against a range of diseases. However, little evidence exists to suggest that supplementation in addition to a healthy diet provides these benefits ${ }^{5-9}$ and in some cases it may in fact be harmful. ${ }^{10}$

The reasons people take supplements are undoubtedly complex and multifactorial ${ }^{11}$ and are set within the current cultural context that emphasises the importance of actively taking personal responsibility for one's health. ${ }^{12}{ }^{13}$ In order to successfully manage one's health, it has been suggested that the 'citizen-come-consumer' (ref. 12, p.356) is compelled to make consumer choices that both demonstrate one's commitment to improving one's health and promise to minimise health risks.

Given this cultural imperative to take responsibility for one's health, it may be important to examine how supplements are framed in the popular press as such framing may inform decisions to purchase and consume vitamins and supplements. ${ }^{14} 15$ News frames, or the central organising ideas, can highlight certain aspects of an issue or topic over others and affect readers' resonance with a story. ${ }^{16}$ Examining news framing 
is particularly important in this context given that the public continues to get much of its information about health and science from the popular press. ${ }^{17}$ Studies have also shown that media coverage, in addition to aggressive marketing strategies, ${ }^{18}$ can have an impact on perceived health beliefs and utilisation patterns. ${ }^{19}$ While the recursive relationship between the media, science and public opinion is complex, ${ }^{20}$ for example, the media both shapes and reflects public perceptions, research has consistently indicated that news media, including newspapers, comprise one of the most important sources of health information for the adult general public, ${ }^{21}{ }^{22}$ although the influence of the internet as a source of news and information is growing. ${ }^{23}$

Given the popularity and health implications of vitamins and supplements, an analysis of news media representations may provide valuable insights that could inform future approaches to public, patient and health professional education. While researchers have previously examined and critiqued the misrepresentation of health-related issues in the popular media ${ }^{24} 25$ and some research has been conducted on portrayals of dietary supplements in magazines ${ }^{26}$ and advertisements, ${ }^{27}$ there has, to date, been little analysis of news media coverage related to the value of vitamins or supplements. As such, this study provides a systematic analysis of how one of the most widely consumed supplements, vitamin $\mathrm{D}$, has been portrayed in the popular press and identifies the dominant messages conveyed around vitamin $\mathrm{D}$, health and the need for supplementation.

\section{THE EVIDENCE SURROUNDING THE NEED FOR VITAMIN D SUPPLEMENTATION}

Vitamin D has received a great deal of attention in the popular press over the past few years. Headlines have, for example, declared a "'Plethora' of diseases caused by vitamin $\mathrm{D}^{\text {"28 }}$ and that increased vitamin $\mathrm{D}$ supplementation/fortification "could stop 'modern' diseases." However, the state of the existing evidence around the health benefits of vitamin $\mathrm{D}$ supplementation is best described as unsettled. ${ }^{30}{ }^{31} \mathrm{~A}$ recent trial sequential meta-analysis ${ }^{32}$ reported on the results from 40 randomised controlled trials (roughly 100000 patients) of vitamin D supplementation alone or vitamin D plus calcium. Most studies followed participants for at least 1 year and in some cases for up to 5-7 years. When looking at the important clinical end points of myocardial infarction or ischaemic heart disease, stroke or cerebrovascular disease, cancer, and mortality, vitamin D supplementation did not significantly reduce risk of these outcomes. Vitamin D supplementation combined with calcium did show a statistically significant reduction in total fractures (8\% relative reduction). There were also no reported negative outcomes associated with supplementation in these studies. The authors concluded, "Available evidence does not lend support to vitamin D supplementation and it is very unlikely that the results of a future single randomised clinical trial will materially alter the results from current meta-analyses" (ref. 32, p.318). These findings provide some support for vitamin D combined with calcium for reducing fracture risk, but suggest other health claims associated with vitamin D supplementation are not currently supported by the literature.

To address dietary requirements and assessment of vitamin D levels, a comprehensive report was recently completed by the Institute of Medicine (IOM) ${ }^{33} 34$ The IOM committee tasked with determining the North American population needs of vitamin $\mathrm{D}$ and calcium concluded that higher concentrations of vitamin D "were not consistently associated with greater benefit, and for some outcomes U-shaped associations were observed, with risks at both low and high levels" (ref. 34, p.53) and "the prevalence of vitamin D inadequacy in North America has been overestimated" (ref. 34, p.53). For some conditions, such as obesity, the causal relation might actually run counter to conventional wisdomthat is, the condition (increase in adipose tissue) results in lower vitamin $\mathrm{D}$ concentrations and not the other way around. ${ }^{35}$ Another recent meta-analysis concluded "[d]espite a few hundred systematic reviews and meta-analyses, highly convincing evidence of a clear role of vitamin D does not exist for any outcome" (ref. 36, abstract). This umbrella review examined over 200 meta-analyses and systematic reviews and reported a probable evidence of association between vitamin $\mathrm{D}$ concentrations and birth weight, maternal vitamin $\mathrm{D}$ status at term, dental caries in children and parathyroid hormone concentration in patients experiencing chronic kidney disease requiring dialysis. However, the authors concluded there was no convincing evidence to support universal vitamin D supplementation-a conclusion that fits with the work of others. ${ }^{32} 3637$

While these conclusions are somewhat definitive in tone, others in the scientific community have been more cautious, emphasising the equivocal nature of the research surrounding the health value of population wide vitamin D supplementation. ${ }^{30} 31$

Given the equivocal and evolving nature of the vitamin D research, ${ }^{32} 36{ }^{37}$ definitive news headlines and their accompanying stories and testimonies may not provide the public with an accurate picture of the relevant science. Furthermore, such stories may-for better or worse-help to drive the market for vitamin $\mathrm{D}$, which some industry reports suggest has grown significantly over the past few years. ${ }^{38-40}$ Indeed, some have suggested that market growth for the sale of vitamin D supplements has reached triple digits and is worth hundreds of millions of dollars. ${ }^{40}$

For the purposes of our study, we do not need to take a stand on the value of vitamin D supplementation; as this is a complex issue (involving biomarkers and the multiple functions of vitamin $\mathrm{D}$ in the body and through the lifecycle). We also do not address the use of vitamin $\mathrm{D}$ for specific, vulnerable populations ${ }^{41}$ or those 
that clearly have vitamin D status that would be associated with important health outcomes like rickets. Instead, we merely seek to highlight that even a cursory review of the relevant academic literature reveals the science around the evidence that the population requires vitamin $\mathrm{D}$ supplementation for optimal health and prevention of diseases is far from conclusive.

The evolving and conflicting nature of the relevant scientific research, outlined briefly above, the absence of research that examines media representation of vitamins and supplements, and the substantial media coverage on vitamin D present a timely opportunity to explore the nature and tone of the media attention paid to this popular vitamin supplement.

\section{METHODS}

Our study sought to understand how the news media framed vitamin D supplementation and whether the framing changed over a 5-year period. Our study was modelled after previous studies that took an inductive approach to analysing the content of print news media; ${ }^{24} 25$ we conducted a content analysis of print articles appearing in elite newspapers that addressed vitamin D over a 5-year period (2009-2014). Search terms included: 'vitamin D' and 'health'. The Factiva database was used to collect newspaper articles about vitamin D in elite newspapers in Canada, the USA and the UK. The search was limited to the top five daily newspapers in a broadsheet format in each country based on recent circulation reports. ${ }^{42} 43$ Our initial search yielded 408 results. Articles were excluded from analysis if vitamin D was not linked to discussions of health or supplementation, or if vitamin D was not a general focus of the article. Our final data set consisted of 294 newspaper articles published between January 2009 and January 2014.

Exploratory qualitative coding was initially conducted on a random sample of 40 articles (approximately 10\%) from the entire sample. ${ }^{44}$ Based on recurring themes that emerged during initial qualitative coding, a coding instrument was developed which was organised into three sections. The first section included general, descriptive information about the publication. The second section captured the health conditions discussed in relation to vitamin $\mathrm{D}$, whether vitamin $\mathrm{D}$ supplementation was mentioned and/or recommended, whether the article referred to a specific research study about vitamin $\mathrm{D}$ and the extent of the information provided, and whether the potential harms of vitamin D supplementation were discussed. Finally, each article was coded as being overall supportive of, skeptical of, merely descriptive or as presenting multiple perspectives on vitamin D supplementation. For the purposes of this study, these items were considered important elements in the framing, or central organising ideas, of representations of vitamin D supplementation in news media.
Two researchers each coded half of the data set. All articles were coded in Excel and data were tallied using SPSS V.22. A random sample of $20 \%$ of the articles was then coded by a third coder who was previously uninvolved in the project. Inter-rater reliability was then calculated on SPSS V.22 using Cohen's $\kappa$. The results of inter-rater reliability for all items ranged between $\kappa=0.644$ and 0.86 with an average score of $\kappa=0.724$, indicating substantial to almost perfect agreement. ${ }^{45}$

\section{RESULTS}

Our results suggest that vitamin D garnered considerable media attention over the 5-year period of interest. Vitamin D coverage peaked in 2010 (which may have been influenced by the release of the revised vitamin $\mathrm{D}$ recommendations by the IOM in November $2010^{33}$ ), and showed only a slight decline in subsequent years. While newspaper coverage was most prominent in Canada, media attention was fairly evenly distributed between all three countries, as shown in table 1 . The largest number of newspaper articles were featured in health and lifestyle sections (48\%), followed by the news and front-page sections (31\%).

\section{What's the big deal about $\mathbf{D}$ ?}

Our content analysis revealed the major themes used in media coverage of vitamin D. In general, articles frequently identified and exalted vitamin D's role in maintaining or promoting good health and in preventing chronic disease. The most common theme overall was: "adequate vitamin D is necessary for good health" $(57 \%$ articles). Most articles contained several themes. Other major themes included, "vitamin D supplements may be necessary for good health and the prevention of chronic disease" (36\% articles), "it is impossible or difficult to get vitamin D from natural sources" (28\% articles) and "vitamin D deficiency is widespread and cause for

\begin{tabular}{llc} 
Table 1 & Newspapers included in sample \\
\hline Newspaper title & Country & Number of articles \\
\hline Globe and Mail & Canada & 45 \\
Montreal Gazette & Canada & 9 \\
National Post & Canada & 12 \\
Toronto Star & Canada & 19 \\
Vancouver Sun & Canada & 18 \\
The Los Angeles Times & USA & 11 \\
The New York Times & USA & 15 \\
USA Today & USA & 11 \\
The Wall Street Journal & USA & 24 \\
The Washington Post & USA & 26 \\
The Daily Telegraph & UK & 9 \\
Financial Times & UK & 8 \\
The Guardian & UK & 19 \\
The Independent & UK & 11 \\
The Times (London) & UK & 57 \\
Total & & 294 \\
\hline
\end{tabular}


Figure 1 Most frequently named health conditions discussed in relationship to vitamin $D$ in newspapers over 5 years.

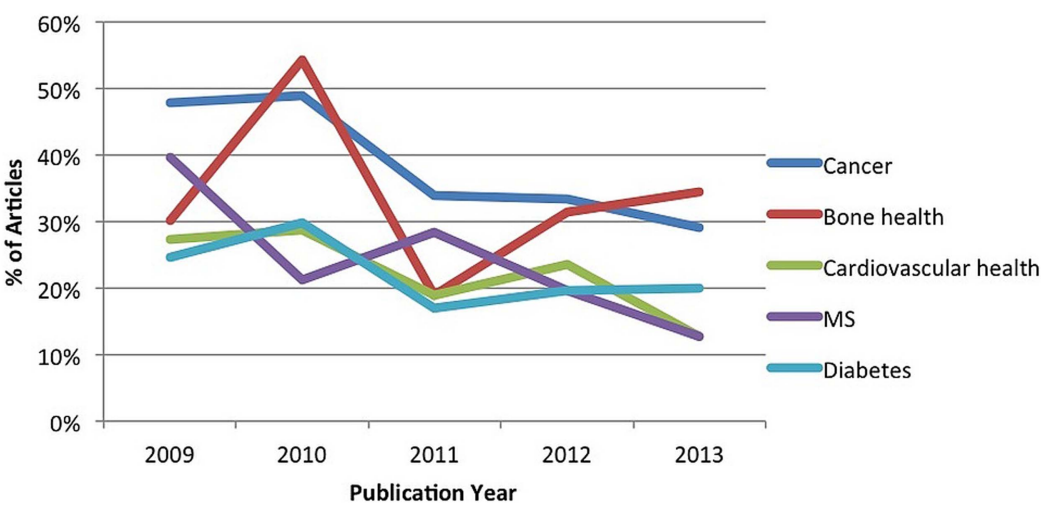

concern" (30\% articles). Overall, the themes in news articles positioned vitamin $\mathrm{D}$ as important for good health, but also suggested it is difficult to achieve sufficient vitamin D levels without supplementation, and that deficiency is a widespread concern.

Articles were also coded to identify the specific health conditions linked to vitamin D. In total, newspaper articles named 40 different health conditions associated with vitamin D. Overall, cancer was mentioned most frequently (43\%), followed by bone health (39\%). After cancer and bone health, newspaper articles cited multiple sclerosis (MS) (28\%), cardiovascular health (25\%) and diabetes (24\%) most frequently. Interestingly, these conditions varied slightly by year, as shown in figure 1 , but cancer and bone health remained relatively steady.

Although these were the most frequently mentioned health concerns, vitamin D was credited for preventing or decreasing the risk of a vast array of health conditions ranging from hair loss, influenza, the common cold, Parkinson's disease and for assisting with muscle recovery. Furthermore, the majority of articles (88\%) listed more than one health concern in connection to poor vitamin $\mathrm{D}$ status. As a result, an overarching narrative emerged that celebrated vitamin $\mathrm{D}$ as a wonder drug that is 'good for everything'.

To supplement or not to supplement?

In light of the zeal with which the North American population purchases and consumes vitamin supplements, and given the media's emphasis on vitamin D's role in a wide range of health conditions, we examined how media coverage addressed the specific issue of vitamin D supplementation. Our analysis revealed $86 \%$ of newspaper articles explicitly referred to vitamin D supplementation. Of these, 59\% of newspaper articles suggested 'supplementation may be necessary for good health' while $21 \%$ more assertively declared 'supplementation is necessary for good health'. In other words, $80 \%$ of newspaper articles suggest supplementation is or may be necessary (figure 2).

It is important to note, however, some newspaper articles, although supportive of vitamin D supplementation overall, were moderate in their approach. For example, $25 \%$ of articles suggested that more research is needed before unequivocal guidance around supplementation is possible. Some articles $(8 \%)$ also made mention of the potential harms of too much vitamin $\mathrm{D}$.

Importantly, many newspaper articles utilised the inverted pyramid style, ${ }^{46}$ which often puts more detailed information, such as the potential for harm further down in the article. We coded for the tone of the entire article, but it may be that if audiences read only the first part of the article, they may not read the more nuanced, detailed pieces of information included in the article.

We also sought to identify if vitamin $\mathrm{D}$ daily intake recommendations for the general public were attributed to any expert, professional or governing body, and if so, which one. Of the newspaper articles $(53 \%)$ that provided these recommendations for the general public, $58 \%$ of articles failed to attribute the recommended intake to any expert body. Of those articles that did provide recommendations and attributed them to a professional body, IOM was the most frequently cited (13\%), followed by Health Canada and the Cancer Society of Canada (10\%).

Many articles suggested that obtaining vitamin D through dietary means and sun exposure was preferable to supplementation, and $57 \%$ of articles identified one or more dietary sources of vitamin $\mathrm{D}$, such as fortified

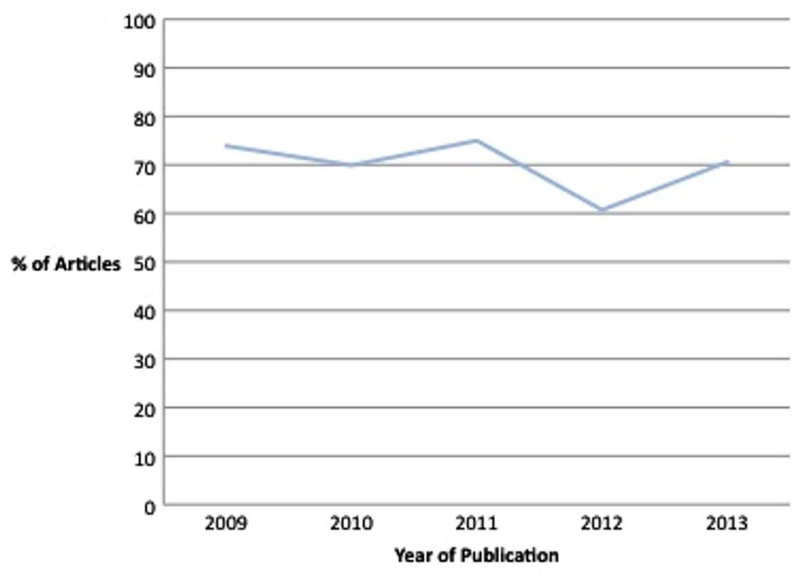

Figure 2 Percentage of articles that utilised one or both of the frames 'supplementation may be beneficial' and/or 'supplementation is necessary' by year. 
milk and some fish. However, articles simultaneously reminded readers that sufficient vitamin $\mathrm{D}$ is difficult to obtain through these non-supplementary means; indeed, this was one of the primary themes about vitamin D aforementioned. Therefore, although articles often acknowledged that non-supplementary sources of vitamin $\mathrm{D}$ were preferable, they also indicated that this approach would likely fail to meet recommendations. As a result we interpreted these discussions as contributing to general support for supplementation.

\section{Deciphering the science: accurate messages in the news?}

The ongoing scientific research on vitamin $D$ was reflected and, at times, explicitly noted in the news media coverage. Of the articles that discussed supplementation, $40 \%$ of newspaper articles referred to one or more specific scientific research studies (ie, a peerreviewed journal article) on vitamin $\mathrm{D}$. These studies were positioned as 'evidence' around vitamin D supplementation and vitamin D's role in specific health conditions. In addition, $35 \%$ of newspaper articles provided details that extended beyond the study's overall conclusions (ie, type of study, sample population and size).

We also coded articles to assess whether news articles interpreted the research as an endorsement of vitamin D supplementation. Our results showed $56 \%$ of those newspaper articles that mentioned research did not interpret the research as taking an explicit stand one way or the other on supplementation. However, $22 \%$ of the articles that mentioned research did interpret the research as an endorsement of supplementation.

Given the ongoing scholarly debate surrounding vitamin $\mathrm{D}$, we analysed these data to identify any potential change in how the science was positioned over the 5 -year sample period. We found the interpretation of research as endorsement of vitamin D supplementation dropped noticeably in 2012 as seen in figure 3. This may reflect the increasing number of research studies that do not call for or support supplementation, or a more cautious approach to interpretation on part of the news media. However, despite this decline in referencing scientific support for supplementation, articles maintained a supportive tone in favour of supplementation overall.

\section{DISCUSSION}

Our results found several consistencies in newspaper coverage of vitamin D. First, the content analysis revealed that newspaper coverage represented vitamin D in a favourable light and suggested it was positively linked to good health and the prevention of chronic diseases. We suggest this is a fair reflection of the science as adequate levels of vitamin $\mathrm{D}$ are, obviously, required for good health. Most of the controversy in the literature is not about whether vitamin $\mathrm{D}$ is needed, but about the amount we should get, whether natural sources are sufficient, and the need for supplementation. Second, newspapers conveyed overall support for vitamin D

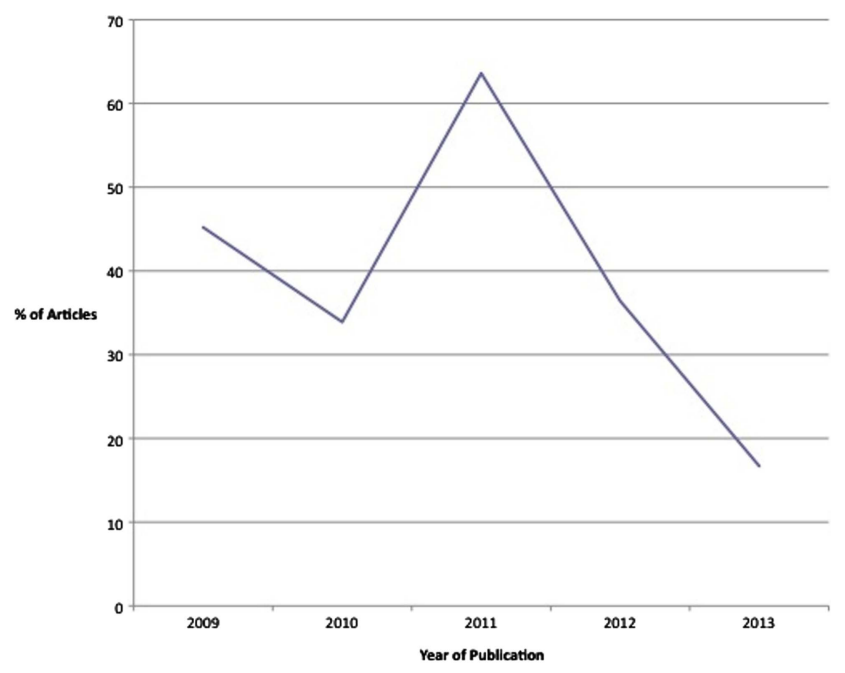

Figure 3 Percentage of articles citing research about vitamin $D$ that interpreted research as endorsement of supplementation by year.

supplementation. Given the equivocal nature of the relevant evidence, this is not an appropriate representation of the science nor consistent with existing policy recommendations. ${ }^{33} 47$

Third, despite the equivocal nature of scientific evidence, even on frequently studied outcomes such as cancer, fractures, cardiovascular health and all-cause mortality, ${ }^{32} 3637$ media coverage overall suggested an established link between vitamin $\mathrm{D}$ and multiple health conditions beyond these. However, potential harm of excessive vitamin D levels and supplementation was very rarely discussed. Therefore, vitamin D supplementation was constructed as risk-free and as providing myriad potential health benefits.

This study is one of few to study media representations of vitamins or supplements. Our findings are consistent with other research of media coverage of health issues, which has shown that news stories about medicine and health emphasise potential benefits and downplay potential harms and limitations. ${ }^{48}{ }^{49}$ Our results also indicate that media coverage was inconsistent and at times contradictory-which, given the state of the science, is not surprising. For example, articles reported inconsistent daily intake recommendations, which may create confusion among readers. ${ }^{19}$ Recent research has also shown both health professionals and the general public are uncertain about many aspects of vitamin $\mathrm{D}$, including how much is needed per day and how much can be easily obtained through natural sources. ${ }^{50}$

Overall, results of the content analysis demonstrate that the print news media often frame vitamin $\mathrm{D}$ and supplementation in terms of the health benefits of vitamin D for everything. While some articles did include qualifying details regarding potential risks and the need for additional research, the positive framing of vitamin $\mathrm{D}$ in news articles draws readers' attention towards supplementation while downplaying these 
risks. ${ }^{15}$ This framing may resonate particularly with readers who were already inclined towards vitamin supplementation, thus providing them little reason to not supplement. ${ }^{14}$

We know the media is a powerful, persuasive source of health information. ${ }^{51} 52$ Given our findings that the popular press has been consistently endorsing supplementation, it seems reasonable to conclude the popular press is, at least in part, helping to fuel the demand for vitamin D supplements and to the confusion about its value. This framing of vitamin $\mathrm{D}$ supplementation may be interacting with salient ideas about the need to take responsibility for one's health, which is often demonstrated through consumer behaviour and other health-related decisions. ${ }^{12}{ }^{13}$ However, the actual impact of media on public perceptions was beyond the scope of this study and could be the subject of future research. Our study also highlights the need for good, independent and reliable sources of health information that present a more nuanced and contextualised picture of the relevant science.

\section{IMPLICATIONS FOR FUTURE RESEARCH}

This study examined a large number of print news articles but it is important to note potential limitations. For example, we did not examine the content or influence of popular vitamin D information websites such as http://www.vitamindcouncil.org or of social media outlets such as Facebook, YouTube and Twitter. However, social media are becoming an increasingly important source of health information for the general public. ${ }^{53-55}$

Therefore, future research should examine how vitamin $\mathrm{D}$ is represented in social media and on popular health-related information websites to determine how the general public integrates and makes sense of these diverse sources of information. It would also be important to examine the public's perceptions of the relationship between vitamin $\mathrm{D}$ and health and their beliefs about supplementation. Bennett and colleagues ${ }^{50}$ provide an important starting point and future research could examine more explicitly what messages the general public takes home from media coverage of vitamin D. Finally, future research that captured the perspectives of health professionals would be important.

\author{
Author affiliations \\ ${ }^{1}$ Health Law Institute, Faculty of Law, University of Alberta, Edmonton, \\ Alberta, Canada \\ ${ }^{2}$ Faculty of Pharmaceutical Sciences, University of British Columbia, \\ Vancouver, British Columbia, Canada \\ ${ }^{3}$ School of Linguistics and Language Studies, Carleton University, Ottawa, \\ Ontario, Canada \\ ${ }^{4}$ Department of Agricultural, Food and Nutritional Science, University of \\ Alberta, Edmonton, Alberta, Canada
}

Acknowledgements This research was generously supported by the Trudeau Foundation and the Canada Research Chairs Program. The authors would like to thank Brice Goldfeldt and Frances Wallace for their assistance in coding the data, Sean Stolp for his assistance with analysis, Kalina Kamenova for her contribution to the coding framework, and the University of Alberta's Health Law Institute for administrative support.

Contributors TC conceptualised the study and assisted with analysis. MC collected, coded and contributed to analysis. CR contributed to analysis. TC MC, JPM, CR and CJF reviewed data and contributed to writing the manuscript.

Funding This research received no specific grant from any funding agency in the public, commercial or not-for-profit sectors.

\section{Competing interests None.}

Provenance and peer review Not commissioned; externally peer reviewed.

Data sharing statement Data set consisting of coded articles available on request from the corresponding author Tim Caulfield; caulfield@ualberta.ca.

Open Access This is an Open Access article distributed in accordance with the Creative Commons Attribution Non Commercial (CC BY-NC 4.0) license, which permits others to distribute, remix, adapt, build upon this work noncommercially, and license their derivative works on different terms, provided the original work is properly cited and the use is non-commercial. See: http:// creativecommons.org/licenses/by-nc/4.0/

\section{REFERENCES}

1. Fortmann SP, Burda BU, Senger CA, et al. Vitamin and mineral supplements in the primary prevention of cardiovascular disease and cancer: an updated systematic evidence review for the U.S Preventive Services Task Force. Ann Intern Med 2013;159:824-34

2. Lamas GA, Boineau R, Goertz $C$, et al. Oral high-dose multivitamins and minerals after myocardial infarction: a randomized trial. Ann Intern Med 2013;159:797-805.

3. Community Health Survey. Statistics Canada. 2004. http://www. statcan.gc.ca/pub/82-003-x/2010004/article/11349/findingsresultats-eng.htmhttp://www.statcan.gc.ca/pub/82-003-x/2010004/ article/11349/findings-resultats-eng.htm

4. Bailey RL, Fulgoni VL, Keast DR, et al. Examination of vitamin intakes among US adults by dietary supplement use. J Acad Nutr Diet 2012;112:657-63.

5. Blendon RJ, Benson JM, Botta MD, et al. Users' views of dietary supplements. JAMA Intern Med 2013;173:74-6.

6. Dwyer J, Nahin RL, Rogers GT, et al. Prevalence and predictors of children's dietary supplement use: the 2007 National Health Interview Survey. Am J Clin Nutr 2013;97:1331-7.

7. Bailey RL, Gahche JJ, Miller PE, et al. Why US adults use dietary supplements. JAMA Intern Med 2013;173:355-61.

8. Martínez ME, Jacobs ET, Baron JA, et al. Dietary supplements and cancer prevention: balancing potential benefits against proven harms. JNCI J Natl Cancer Inst 2012;104:732-9.

9. Fan X, Lee KS, Frazier SK, et al. The use of, and perceptions about, dietary supplements among patients with heart failure. Eur $J$ Cardiovasc Nurs 2014;13:311-19 (cited 20 July 2014). http://cnu. sagepub.com/content/13/4/311

10. Bjelakovic G, Nikolova D, Gluud LL, et al. Antioxidant supplements for prevention of mortality in healthy participants and patients with various diseases. Cochrane Database Syst Rev 2012;3:CD007176.

11. Nichter M, Thompson JJ. For my wellness, not just my illness: North Americans' use of dietary supplements. Cult Med Psychiatry 2006;30:175-222.

12. Fries CJ. Governing the health of the hybrid self: integrative medicine, neoliberalism and the shifting biopolitics of subjectivity Health Soc Rev 2008;17:353-67.

13. Petersen A, Lupton D. The new public health: discourses, knowledges, strategies. Thousand Oaks: Sage, 1996.

14. Nisbet MC. Communicating climate change: why frames matter for public engagement. Environment 2009;51:12-23.

15. Scheufele DA. Framing as a theory of media effects. J Commun 1999;49:103-22.

16. Gamson WA, Modigliani A. Media discourse and public opinion on nuclear power: a constructionist approach. AJS 1989;95:1-37.

17. Geller G, Bernhardt BA, Holtzman NA. The media and public reaction to genetic research. JAMA 2002;287:773.

18. Story M, French S. Food advertising and marketing directed at children and adolescents in the U.S. Int J Behav Nutr Phys Act 2004;1:3-17.

19. Nagler $\mathrm{RH}$. Adverse outcomes associated with media exposure to contradictory nutrition messages. J Health Commun 2014;19:24-40. 
20. Fahnestock J. Accommodating science: the rhetorical life of scientific facts. Written Comm 1998;15:330-50.

21. Percheski C, Hargittai E. Health information-seeking in the digital age. J Am Coll Health 2011;59:379-86.

22. Dutta-Bergman MJ. Primary sources of health information: comparisons in the domain of health attitudes, health cognitions, and health behaviors. Health Commun 2004;16:273-88.

23. Internet gains on television as public's main news source. 4 January 2011 (cited 18 June 2014). http://www.peoplepress.org/2011/01/04/ internet-gains-on-television-as-publics-main-news-source/

24. Zarzeczny A, Rachul C, Nisbet MC, et al. Stem cell clinics in the news. Nat Biotechnol 2010;28:1243-6.

25. Kamenova K, Reshef A, Caulfield T. Angelina Jolie's faulty gene: newspaper coverage of a celebrity's preventive bilateral mastectomy in Canada, the United States, and the United Kingdom. Genet Med 2013;16:522-8.

26. Kava R, Meister KA, Whelan EM, et al. Dietary supplement safety information popular among older readers. J Health Commun 2002;7:13-23.

27. DeLorme DE, Huh J, Reid LN, et al. Dietary supplement advertising in the US. Int J Advert 2012;31:547-77.

28. Smith R. 'Plethora' of diseases caused by low vitamin D. The Telegraph 12 December 2012.

29. Gillie O. Vitamin D—could it stop 'modern' diseases? The Telegraph 10 March 2014

30. Anonymous. Vitamin D: chasing a myth? (Editorial). Lancet Diabetes Endocrinol 2014;2:1.

31. Kupferschmidt $K$. Uncertain verdict as vitamin $D$ goes on trial. Science 2012;337:1476-8.

32. Bolland MJ, Grey A, Gamble GD, et al. The effect of vitamin D supplementation on skeletal, vascular, or cancer outcomes: a trial sequential meta-analysis. Lancet Diabetes Endocrinol 2014;2:307-20.

33. IOM. Dietary reference intakes for calcium and vitamin D. Report Brief 2011. http://www.iom.edu/Reports/2010/Dietary-ReferenceIntakes-for-calcium-and-vitamin-D.aspx

34. Ross AC, Manson JE, Abrams SA, et al. The 2011 report on dietary reference intakes for calcium and vitamin $D$ from the Institute of Medicine: what clinicians need to know. J Clin Endocrinol Metab 2011;96:53-8.

35. Vimaleswaran KS, Berry DJ, Lu C, et al. Causal relationship between obesity and vitamin $\mathrm{D}$ status: bi-directional Mendelian randomization analysis of multiple cohorts. PLoS Med 2013;10: e1001383.

36. Theodoratou E, Tzoulaki I, Zgaga L, et al. Vitamin D and multiple health outcomes: umbrella review of systematic reviews and meta-analyses of observational studies and randomised trials. BMJ 2014;348:g2035.

37. Chowdhury R, Kunutsor S, Vitezova A, et al. Vitamin D and risk of cause specific death: systematic review and meta-analysis of observational cohort and randomised intervention studies. BMJ 2014;348:g1903.
38. Vitamin D use increased $52 \%$ in past two years. 1 February 2011 (cited 9 March2014). http://www.consumerlab.com/news/Vitamin Supplement_Use_Survey_Report/01_31_2011

39. Feldman $\mathrm{M}$. Is the market for vitamin $\mathrm{D}$ supplements at risk of decline? In: Euromonitor international blog. London: Euromonitor International Ltd. 7 April 2011 (cited 9 March 2014). http://blog. euromonitor.com/2011/04/vitamin-d-supplements-losing-their-star. $\mathrm{html}$

40. Montague-Jones G. Markets: global vitamin D boom remains elusive. 25 March 2010 (cited 9 March 2014). http://www. nutraingredients.com/content/view/print/283513

41. Verbrugge $\mathrm{FH}$, Gielen $\mathrm{E}$, Milisen $\mathrm{K}$, et al. Who should receive calcium and vitamin D supplementation? Age Ageing 2012;41:576-80.

42. Alliance for Audited Media. 2013 (cited 15 December 2013). http:// www.auditedmedia.com/news/research-and-data/ top-25-us-newspapers-for-march-2013.asp

43. The Audit Bureau of Circulation. 2013 (cited 15 December 2013) http://www.abc.org.uk/Certificates-Reports/Our-Reports/

44. Saldaña, J. The coding manual for qualitative researchers. 2nd edn. Los Angeles: Sage, 2013.

45. Landis JR, Koch GG. The measurement of observer agreement for categorical data. Biometrics 1977;33:159-74.

46. Pöttker $\mathrm{H}$. News and its communicative quality: the inverted pyramid -when and why did it appear? Journalism Stud 2003;4:501-11.

47. Health Canada. Vitamin D and calcium: updated dietary reference intakes. n.d. (cited 24 July 2014). http://www.hc-sc.gc.ca/fn-an/ nutrition/vitamin/vita-d-eng.php

48. Cassels A, Hughes MA, Cole C, et al. Drugs in the news: an analysis of Canadian newspaper coverage of new prescription drugs. CMAJ 2003;168:1133-7.

49. Schwitzer G. Addressing tensions when popular media and evidence-based care collide. BMC Med Inform Decis Mak 2013;13 (Suppl 3):S3.

50. Bennett K, Frisby BN, Young LE, et al. Vitamin D: an examination of physician and patient management of health and uncertainty. Qual Health Res 2014;24:375-86.

51. Begley A, Coveney J. Wonder vitamin or mass medication? Media and academic representation of folate fortification as a policy problem in Australia and New Zealand. Aust N Z J Public Health 2010;34:466-71.

52. Caulfield T, Bubela T, Murdoch CJ. Myriad and the mass media: the covering of a gene patent controversy. Genet Med 2007;9:850-5.

53. Logsdon CM, Mittelberg M, Myers J. Use of social media and internet to obtain health information by rural adolescent mothers. Appl Nurs Res. 2014 (cited 20 July 2014). http://www. appliednursingresearch.org/article/S0897-1897(14)00087-1/pdf.

54. Scanfeld D, Scanfelt V, Larson EL. Dissemination of health information through social networks: Twitter and antiobiotics. $A m \mathrm{~J}$ Infect Control 2010;38:182-8.

55. Vance K, Howe W, Dellavalle RP. Social internet sites as a source of public health information. Dermatol Clin 2009;27:133-6. 